\title{
KR-31831, a new synthetic anti-ischemic agent, inhibits in vivo and in vitro angiogenesis
}

\author{
Eui-Yeun $\mathrm{Yi}^{1}$, Shi-Young Park ${ }^{1}$, \\ Hyun Seok Song ${ }^{1,2}$, Myung Jin Son ${ }^{1,2}$, \\ Kyu-Yang $\mathrm{Yi}^{3}$, Sung-En $\mathrm{Yoo}^{3}$ and \\ Yung-Jin Kim ${ }^{1,4}$
}

${ }^{1}$ Department of Molecular Biology

Pusan National University

Busan 609-735, Korea

${ }^{2}$ Department of Neurosurgery

Samsung Medical Center and

Samsung Biomedical Research Institute

Sungkyunkwan University School of Medicine

Seoul 135-710, Korea

${ }^{3}$ Korea Research Institute of Chemical Technology

Daejeon 305-600, Korea

${ }^{4}$ Corresponding author: Tel, 82-51-510-2176;

Fax, 82-51-513-9258; E-mail, yjinkim@pusan.ac.kr

Accepted 24 July 2006

Abbreviations: BAECs, bovine aortic endothelial cells; bFGF, basic fibroblast growth factor; ECM, extracellular matrix; FGFR-2, fibroblast growth factor receptor-2

\footnotetext{
Abstract

Angiogenesis is considered to be an integral process to the growth and spread of solid tumors. Anti-angiogenesis therapy recently has been found to be one of the most promising anti-cancer therapeutic strategies. In this study, we provide several lines of evidences showing that KR-31831, a new benzopyran derivative, has anti-angiogenic activities. KR-31831 inhibited the proliferation, migration, invasion and tube formation of bovine aortic endothelial cells (BAECs), and suppressed the release of matrix metalloproteinase-2 (MMP-2) of BAECs. KR-31831 also inhibited in vivo angiogenesis in mouse Matrigel plug assay. Furthermore, the mRNA expressions of basic fibroblast growth factor (bFGF), fibroblast growth factor receptor-2 (FGFR-2), and vascular endothelial growth factor receptor-2 (VEGFR-2) were decreased by KR-31831. Taken together, these results suggest that KR-31831 acts as a novel angiogenesis inhibitor and might be useful for treating hypervascularized cancers.
}

Keywords: angiogenesis; angiogenesis inhibitors; fibroblast growth factor 2; neoplasms

\section{Introduction}

Angiogenesis is the development of new blood vessels by sprouting from pre-existing endothelium (Folkman and Shing, 1992; Siddiqui et al., 2002), and is significant component of a wide variety of physiological process (e.g. wound healing, embryonic development) and pathological conditions (e.g. diabetic eye disease, tumor growth and spread) (Savani et al., 2001). It is strictly regulated phenomenon and is under the control of balance between angiogenic stimulators and inhibitors (Miao et al., 2002). In addition, complex and diverse cellular actions are implicated in angiogenesis, such as degradation of extracellular matrix (ECM), proliferation and migration of endothelial cells, and morphological differentiation of endothelial cells to form tubes (Folkman, 1990; Lee et al., 2001).

KR-31831, \{(2R,3R,4S)-6-amino-4-[N-(4-chloropheyl)$\mathrm{N}$-(1 H-imidazol-2ylmethyl)amino]-3-hydroxyl-2-meth yl-2-dimethoxymethyl-3,4-dihydro-2H-1-benzopyran\}, is a new synthetic anti-ischemic agent. Benzopyran is one of the most frequently used back-bones of synthetic drugs, including anti-oxidants, anti-hypertensive, and therapeutic agents for ischemia-related diseases. A variety of amines were introduced at the 4-position of benzopyran for the identification of ATP sensitive potassium channel $\left(K_{\text {ATP }}\right)$ openers targeting ischemic diseases, such as myocardial infarction and stroke (Yoo et al., 2001). In addition, some of benzopyran derivatives substituted with a secondary amine including imidazole unexpectedly showed the inhibitory effects on endothelial cell tube formation (Kim et al., 2003).

Therefore, we investigated whether KR-31831 suppresses the angiogenic action of endothelial cells using in vitro and in vivo angiogenesis assays. In consequence, we found that KR-31831 inhibited proliferation, migration, invasion, tube formation, and activation of MMP-2 in BAECs in vitro and inhibited in vivo angiogenesis in mouse Matrigel plug assay. Furthermore, KR-31831 reduced the mRNA expressions of bFGF, FGFR-2 and VEGFR-2 (KDR). 


\section{Materials and Methods}

\section{Materials}

KR-31831 was donated from the Korea Research Institute of Chemical Technology (Daejon, Korea). Matrigel was purchased from Collaborative Biomedical Products (Bedford, MA) and used at a concentration of $10 \mathrm{mg} / \mathrm{ml}$ for the mouse Matrigel plug assay. bFGF and heparin were purchased from Life Technologies (Gaithersberg, MD). [ $\left.{ }^{3} \mathrm{H}\right]$ methylthymidine $(25 \mathrm{Ci} / \mathrm{mmol})$ was purchased from Amersham Pharmacia Biotechnology (Piscataway, NJ).

\section{Animals}

Specific pathogen free (SPF) male C57BL/6 mice were supplied from Hyochang Science (Taegu, Korea). They were provided with autoclaved tap water and lab chow ad libitum and were housed at $23 \pm 0.5^{\circ} \mathrm{C}, 10 \%$ humidity in a $12 \mathrm{~h}$ light-dark cycle.

\section{Mouse Matrigel plug assay}

C57BL/6 mice (7 weeks of age) were injected subcutaneously $500 \mu$ l of Matrigel containing bFGF (100 $\mathrm{ng} / \mathrm{ml})$ and heparin $(50 \mathrm{U} / 500 \mu \mathrm{l})$ with or without KR$31831(2.5$ or $5 \mu \mathrm{g})$. After seven days, the skin of the mouse was pulled back to expose the Matrigel plug, which remained intact. The Matrigel plugs were photographed and hemoglobin content was measured according to the Drabkin method (Drabkin and Ausin, 1932) with Drabkin reagent kit 525 (Sigma, $\mathrm{MO}$ ) for the quantification of blood vessel formation.

\section{Cell culture}

BAECs were grown in DMEM supplemented with heat-inactivated $10 \%$ fetal bovine serum (Life Technologies, NY), $100 \mathrm{U} / \mathrm{ml}$ of penicillin and $100 \mu \mathrm{g} / \mathrm{ml}$ of streptomycin in a $37^{\circ} \mathrm{C}$ incubator with a humidified atmosphere containing $5 \% \mathrm{CO}_{2}$.

\section{$\left[^{3} \mathrm{H}\right]$ thymidine incorporation assay}

BAECs, grown to near confluence in 24-well culture plates, were made quiescent and treated with KR-31831 solved in DMSO for $48 \mathrm{~h}$. Cells were labeled with $25 \mathrm{mCi} / \mathrm{mmol}$ of $\left[{ }^{3} \mathrm{H}\right]$ methylthymidine (Amersham, UK) for $4 \mathrm{~h}$ before the assay. After labeling, unincorporated $\left[{ }^{3} \mathrm{H}\right]$ methylthymidine was removed by washing with $10 \%$ trichloroacetic acid, and then incorporated $\left[{ }^{3} \mathrm{H}\right]$ methylthymidine was extracted in $0.2 \mathrm{M} \mathrm{NaOH}$ and $0.1 \% \mathrm{SDS}$ at $37^{\circ} \mathrm{C}$ for $1 \mathrm{~h}$. The radio-activity from cultures was counted with a liquid scintillation counter (Beckman Instruments, CA).

\section{Wounding migration assay}

BAECs, plated on $60 \mathrm{~mm}$ culture dishes at $90 \%$ confluence, were wounded with a razor blade that is $2 \mathrm{~mm}$ in width and marked at the injury line. After wounding, the cultures were washed with serum-free medium and further incubated in DMEM with $1 \%$ serum, $1 \mathrm{mM}$ thymidine and/or KR-31831. BAECs were allowed to migrate for $24 \mathrm{~h}$ and rinsed with serum-free medium, followed by fixing with absolute methanol and staining with Giemsa. Migration was quantified with counting the number of cells that moved beyond the reference line.

\section{Invasion assay}

Invasiveness of BAECs was analyzed using transwell chambers system with $8 \mu \mathrm{m}$-pore-polycarbonate filter inserts. The lower side of filter was coated with $10 \mu \mathrm{l}$ of type IV collagen ( $3 \mathrm{mg} / \mathrm{ml}$ ), and the upper side was coated with $10 \mu \mathrm{l}$ of Matrigel $(0.5 \mathrm{mg} / \mathrm{ml})$. BAECs $\left(3 \times 10^{4}\right.$ cells/well $)$ and KR-31831 were placed in upper part of the filters and BSA was treated in down part. After $24 \mathrm{~h}$ of incubation at $37^{\circ} \mathrm{C}$, cells on both sides of the membrane were fixed with methanol and stained with hematoxyline/eosin. Cells on the upper surface of the membrane were removed by wiping with cotton swab, and the number of cells on the lower side of the membrane was counted with optical microscopy at $\times 40$ magnification.

\section{Tube formation assay}

BAECs $\left(5 \times 10^{5}\right.$ cells) were seeded on a layer of previously polymerized Matrigel. KR-31831 was treated. After $6 \mathrm{~h}$ of incubation, the morphology of cells were observed under a phase contrast microscope and photographed at $\times 40$ magnification.

\section{Gelatin-based zymography}

The conditioned medium of cultured BAECs was analyzed by the gelatin-based zymography, using slightly modified procedure from Herron et al. (1986). Conditioned medium were separated by SDS-PAGE using $10 \%$ acryl amide copolymerized with 0.33 $\mathrm{mg} / \mathrm{ml}$ gelatin (Sigma, MO). After electrophoresis, the gel was rinsed twice with $2.5 \%$ Triton $\mathrm{X}-100$ for $15 \mathrm{~min}$ and incubated at $37^{\circ} \mathrm{C}$ for $24 \mathrm{~h}$ in incubation buffer (0.05 M Tris- $\mathrm{HCl} \mathrm{pH} 7.5,0.15 \mathrm{M} \mathrm{NaCl}, 0.01 \mathrm{M}$ $\mathrm{CaCl}_{2}, 1 \mu \mathrm{M} \mathrm{ZnCl}$, and $0.02 \% \mathrm{NaN}_{3}$ ). Gelatinase was identified following staining of the gel with Coomassie-brilliant blue R250 and destaining with $7 \%$ acetic acid. The digested area appeared clear on a blue background indicating the location of gelatinase. 


\section{RT-PCR analysis}

Total RNA from BAECs was isolated using Trizol reagent (Life Technologies, NY) according to the manufacturer's instructions. First-stranded cDNA was synthesized by M-MLV reverse transcriptase with $5 \mu \mathrm{g}$ of each DNA-free total RNA sample and oligo (dT)15 (Life Technologies, NY) according to the manufacturer's instructions. Equal amounts of cDNA were subsequently amplified by PCR in a $50 \mu \mathrm{l}$ reaction volume containing $1 \times$ PCR buffer, $200 \mu \mathrm{M}$ dNTPs, $10 \mu \mathrm{M}$ of each specific primer and $1.25 \mathrm{U}$ Taq DNA polymerase (Perkin Elmer, MA). Amplification products were electrophoresed on $1.5 \%$ agarose gels and visualized by ethidium bromide staining under ultraviolet trans-illumination.

\section{Data analysis and statistics}

Data were presented as means $\pm S D$ or as the percentage of control. Statistical comparisons between groups were performed using the Student's $t$ test. ${ }^{*} P<0.05$ was considered statistically significant.

\section{Results}

\section{KR-31831 inhibits in vivo angiogenesis}

The chemical structure of KR-31831 is shown in Figure 1. To determine whether KR-31831 has anti-angiogenic activity, we performed the mouse Matrigel plug assay, an established in vivo angiogenesis model (Passaniti et al., 1992) (Figure 2). As shown in Figure 2A, Matrigel plugs containing bFGF were abundantly filled with intact red blood cells, which indicate the formation of a functional vas-

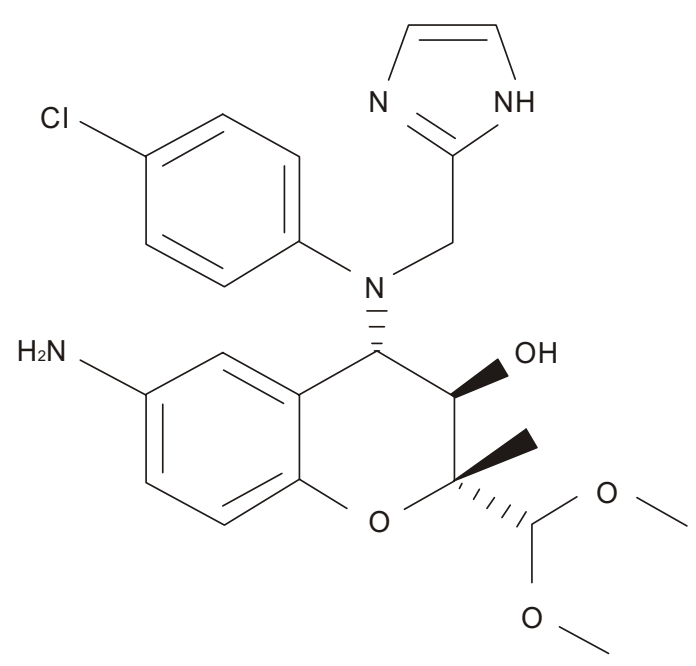

Figure 1. Structure of KR-31831. culature inside the Matrigel, whereas vessels were not observed in the Matrigel alone (blank). Matrigel plug containing KR-31831 had produced fewer vessels as compared with plug containing bFGF, indicating that KR-31831 inhibits the formation of bFGF-induced neomicrovessels. In addition, to quantify the anti-angiogenic effect of KR-31831, we measured the hemoglobin contents inside the Matrigel plugs (Figure 2B). The hemoglobin content of bFGF-treated plug was $30 \mathrm{~g} / \mathrm{dl}$, whereas that of KR-31831-treated plugs was profoundly diminished to about $10 \mathrm{~g} / \mathrm{dl}$. Taken together, these results suggest that KR-31831 has strong anti-angiogenic-activity in vivo.

\section{KR-31831 inhibits proliferation of BAECs}

To determine the effects of KR-31831 on endothelial

A

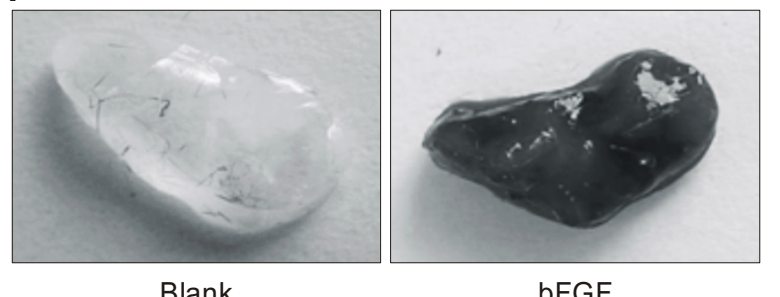

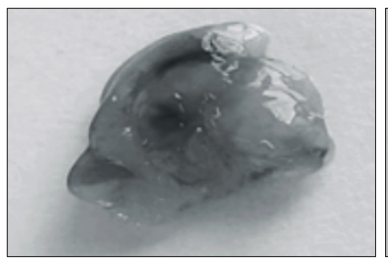

$\mathrm{bFGF}+2.5 \mu \mathrm{g}$

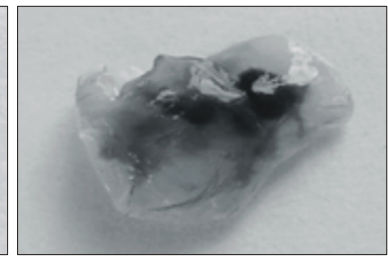

$\mathrm{bFGF}+5 \mu \mathrm{g}$
B

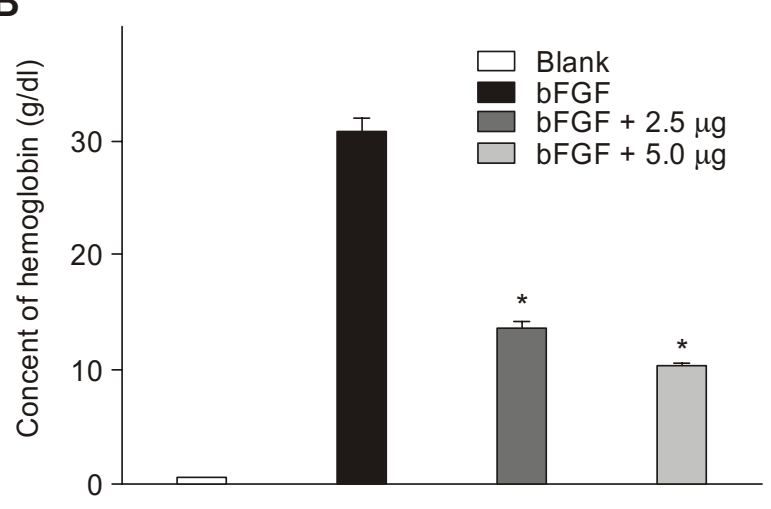

Figure 2. Effect of KR-31831 on in vivo angiogenesis. (A) Matrigel plugs were photographed. $(\times 40)$. (B) Quantification of hemoglobin content. Each value represents the mean $\pm S D$ of at least five animals, and performed in three different experiments. Blank; Matrigel alone. ${ }^{*} P$ $<0.05$ versus hemoglobin content of implants with bFGF. 


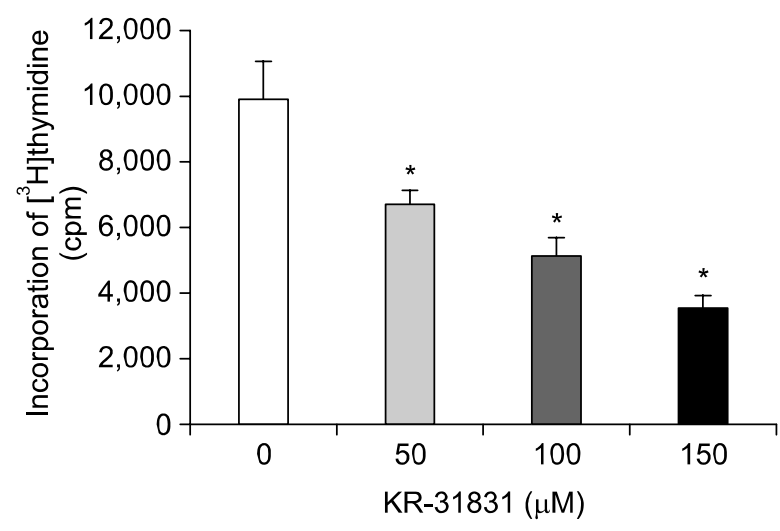

Figure 3. Effect of KR-31831 on proliferation of BAECs. Increasing concentration of KR-31831 reduced the proliferation of BAECs for 48 $h$. Data are mean $\pm S D$ from three independent experiments performed in triplicates. ${ }^{*} P<0.05$ versus control.

cell functions crucial to angiogenesis, its effects on bFGF-induced angiogenesis in vitro were investigated. We first examined the effect of KR-31831 on the viability of BAECs by increasing the concentration of KR-31831 (0 to $200 \mu \mathrm{M})$. The treatment of KR-31831 did not show any cytotoxic effect on BAECs up to $180 \mu \mathrm{M}$ (data not shown). Therefore, the dose ranges of KR-31831 at 50 to $150 \mu \mathrm{M}$ were used in all in vitro angiogenesis experiments. To examine the effect of KR-31831 on the proliferation of BAECs, $\left[{ }^{3} \mathrm{H}\right]$ thymidine incorporation assay was carried out (Figure 3 ). The treatment of KR-31831 for $48 \mathrm{~h}$ significantly decreased the DNA synthesis of BAECs as compared with control in a dose-dependent manner. The treatment of KR-31831 at $150 \mu \mathrm{M}$ showed a $60 \%$ decrease of proliferation as compared with control. This result suggested that KR-31831 inhibits the proliferation of BAECs.

\section{KR-31831 inhibits the activity of migration and invasion in BAECs by reducing the production and activation of MMP-2}

The activity of migration and invasion in endothelial cells is one of the critical features in the formation of new blood vessels and in the repair of injured vessels. We also investigated the effect of KR-31831 on the movement of BAECs from a wounded edge to the open area using wounding migration assay (Figure 4). The treatment of KR-31831 for $24 \mathrm{~h}$ profoundly decreased the migration of BAECs as compared with that of control in a dose-dependent manner (Figure 4A). To examine the effect of KR-31831 on the invasiveness of BAECs, we performed invasion assay with Transwell system. The lower and upper sides of filter were coated with type IV collagen and Matrigel, respectively. KR-
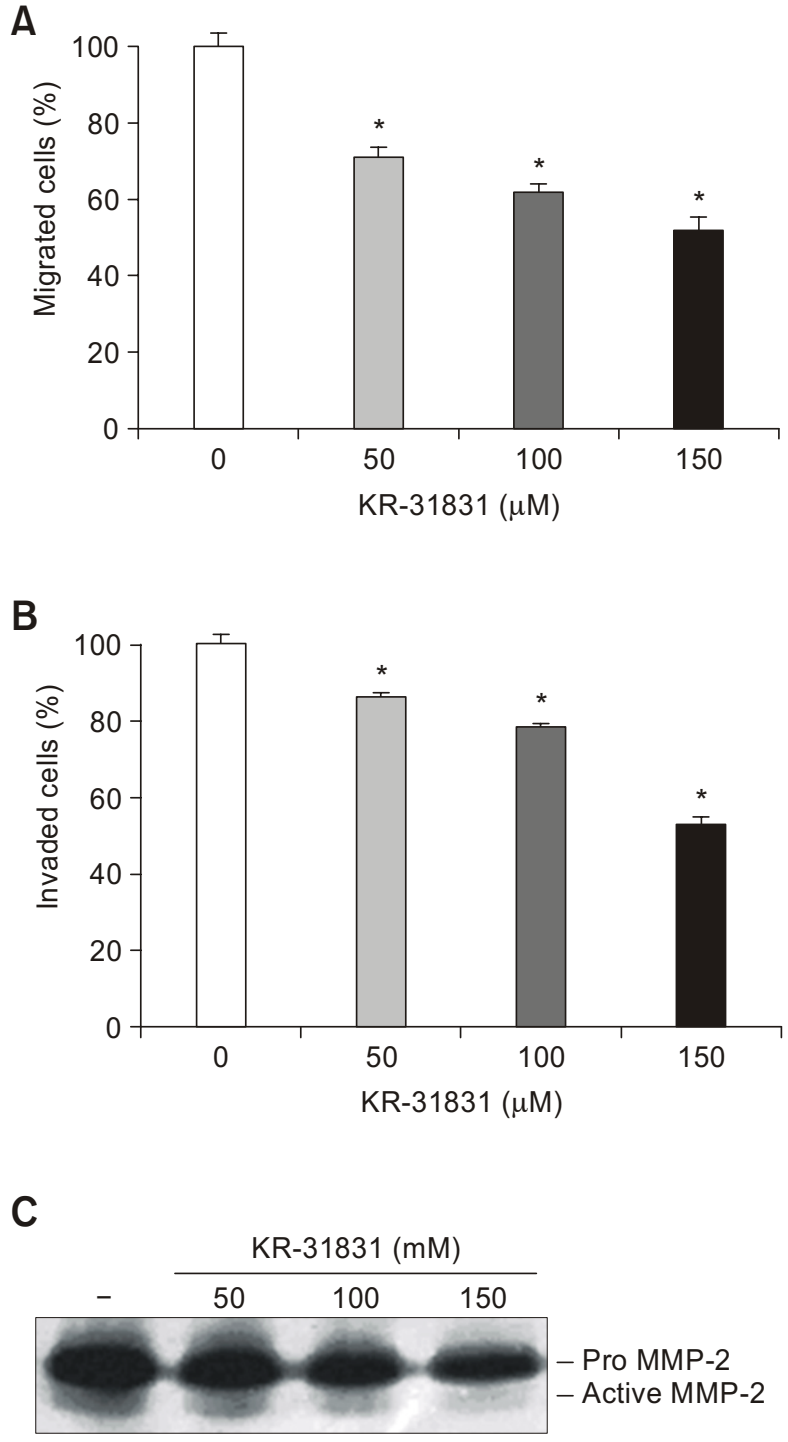

Figure 4. Effect of KR-31831 on the activity of migration and invasion and the production and activation of MMP-2. KR-31831 inhibited the activity of migration (A) and invasion (B) of BAECs in a dose-dependent manner. KR-31831 reduced the production and activation of MMP-2 (C) in a dose-dependent manner. Data are mean \pm SD from three independent experiments performed in triplicates. ${ }^{*} P<0.05$ versus control.

31831 suppressed the invasiveness of BAECs as compared with that of control in a dose-dependent manner after $24 \mathrm{~h}$ of incubation (Figure 4B).

Regulation of extracellular proteolytic activity is important in the process of endothelial cell migration and invasion through the basement membrane and of capillary morphogenesis. Thus, we examined the effect of KR-31831 on the MMP-2 production and activation of BAECs using gelatin-based zymogra- 

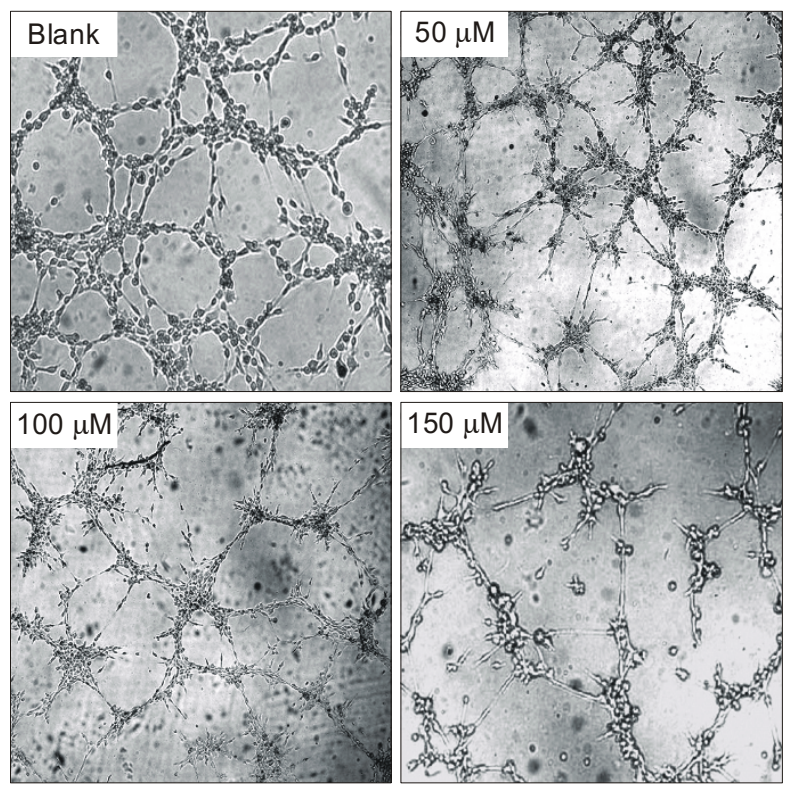

Figure 5. Effect of KR-31831 on the tube formation of BAECs. KR-31831 inhibited the development of capillary-like structure $(\times 40)$.

phy. The treatment of KR-31831 for $24 \mathrm{~h}$ reduced the production of both pro- and active-MMP-2 as compared with those of the control in a dosedependent manner (Figure 4C). These results indicate that KR-31831 inhibits the activity of migration and invasion in BAECs by reducing the production and activation of MMP-2.

\section{KR-31831 inhibits the tube formation of BAECs}

To estimate the effect of KR-31831 on the differentiation of BAECs, we carried out tube formation assay (Folkman and Haudenschild, 1980). BAECs were placed on a growth factor-reduced Matrigelcoated plate and were incubated for $6 \mathrm{~h}$. As shown in Figure 5, BAECs on Matrigel formed blood vessel network in the absence of KR-31831, whereas the treatment of KR-31831 strongly inhibited the formation of tube-like structures in a dose-dependent manner.

\section{KR-31831 down-regulated the mRNA expressions of bFGF, FGFR-2 and VEGFR-2 (KDR)}

To determine which factors were involved in the anti-angiogenic activity of KR-31831, we examined the mRNA expressions of angiogenic factors $\left(\mathrm{VEGF}_{165}\right.$, $\mathrm{VEGF}_{121}$, and $\mathrm{bFGF}$ ) and their receptors (KDR and FGFR-2) in BAECs by KR-31831 treatment using RT-PCR. As shown in Figure 6, the treatment of KR-31831 decreased the mRNA expression of bFGF in a dose dependent manner. However, the

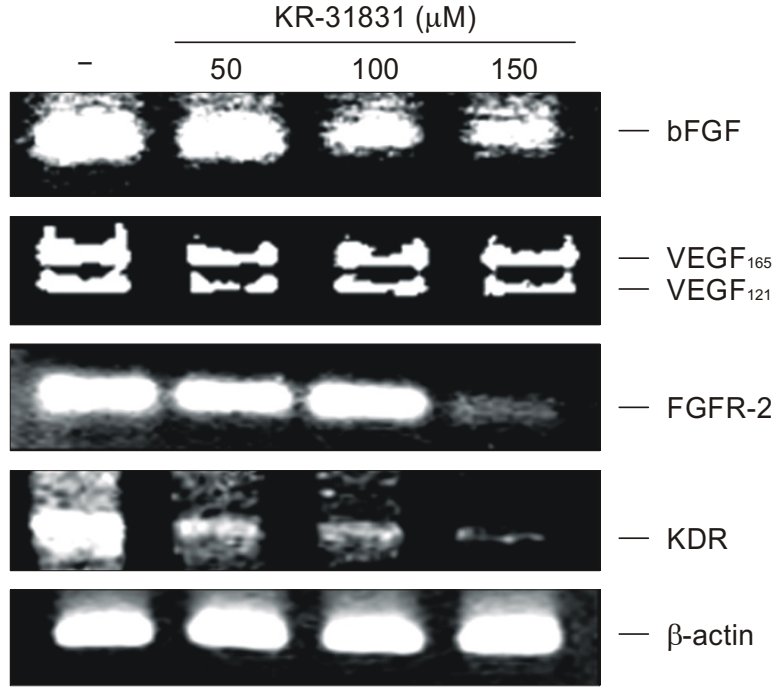

Figure 6. Effect of KR-31831 on the expressions of angiogenesis- associated genes. The mRNA expressions of bFGF, FGFR-2 and VEGFR-2 (KDR) in KR-31831 treated BAECs were analyzed by RT-PCR analysis. Amplification of $\beta$-actin demonstrates comparable RNA amount and quantity among samples.

treatment of KR-31831 did not produce any significant change in VEGF mRNA levels. On the other hand, the mRNA expressions of both FGFR-2 and VEGFR-2 (KDR), which are major functional receptors of key angiogenic factors bFGF and VEGF, were markedly down-regulated by treatment of KR-31831 in a dose-dependent manner. These data suggest that the down-regulated expressions of both FGFR2 and VEGFR-2 (KDR) mRNA may be responsible for the anti-angiogenic action being observed in BAECs treated with KR-31831.

\section{Discussion}

In cancer, the growth of tumor is dependent on the angiogenic growth of new blood vessels. Trials of anti-angiogenic therapy are based on strategies that interfere with angiogenic ligands, their receptors or downstream signaling. Angiogenesis is a complex process involving several cascades; a) enzymatic degradation of vascular basement membrane and interstitial matrices by endothelial cells, b) directed migration and proliferation of endothelial cells to provide cells for the new vessels, c) invasion of endothelial cells and d) formation of capillary-like networks by endothelial cells (Bussolino et al., 1997; Carmeliet and Jain, 2000).

To elucidate the utilization of KR-31831 as an anti-angiogenesis agent, we first determined the anti-angiogenic activity of KR-31831 by performing in vivo mouse Matrigel plug assay. KR-31831 highly 
inhibited the formation of neomicrovessels in Matrigel (Figure 2A), and we noted that these newly synthesized vessels in Matrigel plug containing KR-31831 were not abundantly filled with intact red blood cells (Figure 2B). Also, we observed the effects of KR-31831 on angiogenesis in each step by using in vitro angiogenesis assays. We observed the inhibition of proliferation by KR-31831 (Figure 3). The cells incubated in the presence of KR-31831 lose their proliferative activity in a dose-dependent manner. The migration and invasive activity of BAECs were performed by wounding migration (Figure 4A) and invasion (Figure 4B) assays, since the mobility of endothelial cells, such as migration and invasion, is one of the initiation steps in angiogenesis. KR-31831 significantly reduced both activities of BAECs in a dose-dependent manner.

Matrix Metalloproteinases (MMPs) are secreted as proenzymes and key regulators of extracellular matrix turnover through degradation of a wide variety of extracellular matrix proteins (Giavazzi and Taraboletti, 2001). The regulation of extracellular proteolytic activity is important in the process of endothelial cell migration and invasion, which occur during angiogenesis, and is essential step in tumor invasion and metastasizes (Liekens et al., 2001). On the basis of the fact that the motility of BAECs was profoundly suppressed by KR-31831, we checked the effect of KR-31831 on the production and activation of MMP-2 by using gelatin-based zymography. Expectedly, KR-31831 reduced the production and activation of both pro- and active-MMP-2 (Figure $4 \mathrm{C}$ ). Therefore, the inhibitory effects of KR-31831 on the angiogenesis may be at least in part dependent on the reduction of MMP-2. By performing these in vitro angiogenesis assays, we concluded that KR-31831 has strong inhibitory effects on a series of angiogenic processes, including endothelial cell proliferation, migration, invasion, and tube formation. One of the aspects of the biological relevance of endothelial cell chemotaxis in vitro that is important to the process of angiogenesis is an ability to promote morphological differentiation into capillary-like structure. In the absence of KR-31831, BAECs, placed on the Matrigel, formed short and thick capillary-like networks that seemed to be indicative of angiogenic development, whereas BAECs in the presence of KR-31831 showed reduced tube-like structure (Figure 5).

In addition, tumors produce a wide array of angiogenic molecules during angiogenesis process (Fidler and Ellis, 1994). Therefore, we determined the involvement of KR-31831 in the expressions of several major angiogenic factors and receptors. As shown in Figure 6, the mRNA expressions of bFGF, FGFR-2 and VEGFR-2 (KDR) were remarkably reduced by the treatment of KR-3183, whereas VEGF mRNA expression was not changed. Upon the basis on the fact that KR-31831 strongly downregulates the expressions of KDR/FIk-1 and FGFR-2, we suggest the possibility that KR-31831 might significantly inhibit the KDR/FIk-1 and FGFR-2 tyrosine phosphorylation-linked downstream signal pathways via binding of VEGF and bFGF to their receptors, thereby leading to the suppression of multiple biological responses, including endothelial cell proliferation, migration, differentiation, protease production and angiogenesis.

The inhibition of tumor angiogenesis is a key therapeutic strategy that holds great promise for the advancement of tumor treatment, and a wide range of agents designed to interfere with specific stages of the angiogenic process are currently in development (Herbst et al., 2005). These agents can be considered as either direct inhibitors of the angiogenic process (e.g. endostatin, TNP-470, and matrix metalloproteinase inhibitors) or indirect angiogenesis inhibitors that generally prevent the expression or activity of the tumor protein activating angiogenesis, and of its receptor on endothelial cells (e.g. inhibitor of EGF receptor tyrosine kinase, VEGF receptor and ERBB-2) (Kerbel and Folkman, 2002). In this viewpoint, KR-31831 showing antiangiogenic activity may be able to be used as an anti-tumor as well as anti-ischemic agent.

In summary, the major findings reported here are that a new benzopyran derivative KR-31831 inhibited the in vitro angiogenesis in BAECs and in vivo bFGF-induced neovascularization in mice Matrigel plugs in association with the decreased releases of pro- and active-MMP-2, and expressions of bFGFR2 and VEGFR-2 mRNA. Therefore, we suggest that KR-31831 exhibits strong anti-angiogenic actions and also may have potential to be a useful inhibitor of the large number of serious diseases characterized by upregulated angiogenesis. Further study is required to define more precisely the molecular mechanisms by which KR-31831 modulates endothelial cell function as well as gene expression, and especially, the effects of KR-31831-reduced expressions of both KDR/FIt-1 and FGFR-2 on their downstream signaling pathways.

\section{Acknowledgement}

This study was supported in part by a grant of the 2003 Korean National Cancer Control Program (0220060-I), Ministry of Health \& Welfare, R.O.K.

\section{References}

Bussolino F, Mantovani A, Persico G. Molecular mechanisms 
of blood vessel formation. Trends Biochem Sci 1997;22:251-6

Carmeliet P, Jain RK. Angiogenesis in cancer and other diseases. Nature 2000;407:249-57

Drabkin DS, Ausin JH. Spectrophotomeric constans for common hemoglobin derivaties in human, dog, and rabbit blood. J Biol Chem 1932;98:719

Fidler IJ, Ellis LM. The implications of angiogenesis for the biology and therapy of cancer metastasis. Cell 1994;79:185-8

Folkman J, Haudenschild C. Angiogenesis in vitro. Nature 1980;288:551-6

Folkman $\mathrm{J}$. What is the evidence that tumors are angiogenesis dependent? J Natl Cancer Inst 1990;82:4-6

Folkman J, Shing Y. Angiogenesis. J Biol Chem 1992; 267:10931-4

Giavazzi R, Taraboletti G. Preclinical development of metalloproteasis inhibitors in cancer therapy. Ciritical Rev Oncol/ Hematol 2001;37:53-60

Herbst RS, Onn A, Sandler A. Angiogenesis and lung cancer: prognostic and therapeutic implications. J Clin Oncol 2005; 23:3243-56

Kerbel R, Folkman J. Clinical translation of angiogenesis inhibitors. Nat Rev Cancer 2002;2:727-39

Kim NJ, Lee SK, Yi YK, Yoo SE, Kim GC, Lee CO, Park SH, Lee $\mathrm{BH}$. Identification of a novel aniangiogenic agent; 4-(N-imidazol-2-ylmethyl)amino benzopyran analogues.
Bioorg Med Chem Lett 2003;13:1661-3

Lee MS, Moon EJ, Lee SW, Kim MS, Kim KW, Kim YJ. Angiogenic activity of pyruvic acid in in vivo and in vitro angiogenesis models. Cancer Res 2001;61:3290-3

Liekens S, Clercq ED, Neyts J. Angiogenesis: regulators and clinical applications. Biochem Pharm 2001;61:253-70

Miao RQ, Agata J, Chao L, Chao J. Kallistatin is a new inhibitor of angiogenesis and tumor growth. Blood 2002;100:3245-52

Passaniti A, Taylor RM, Pili R, Guo Y, Long PV, Haney JA, Pauly RR, Grant DS, Martin GR. A simple, quantitative method for assessing antiogenesis and antiangiogenic agents using reconstituted basement membrane, heparin, and fibroblast growth factor. Lab Investig 1992;67:519-28

Savani RC, Cao G, Pooler PM, Zaman A, Zhou Z. Differential involvement of the hyaluronan $(\mathrm{HA})$ receptors $\mathrm{CD} 44$ and receptor for $\mathrm{HA}$-mediated motility in endothelial cell function and angiogenesis. J Biol Chem 2001;276:36770-8

Siddiqui FA, Desai H, Siddiqui TF, Francis JL. Hemoglobin induces the expression and secretion of vascular endothelial growth factor from human malignant cells. Hematol J 2002; 3:264-70

Yoo SE, Yi KY, Lee SK, Suh JH, Kim NJ, Lee BH, Seo HW, Kim SO, Lee DH, Lim H, Shin HS. A Novel Anti-ischemic ATPsensitive potassium channel $\left(K_{\text {ATP }}\right)$ opener without vasorelaxation: $N$-(6-aminobenzopyranyl)- $N$ '-benzyl- $N$ "cyanoguanidine. J Med Chem 2001;44:4207-15 